\title{
Rapid formation of nanostructures in Au films using a CO laser
}

$\operatorname{AUTHOR}(\mathrm{S})$ :

Maurya, Sandeep Kumar; Uto, Yuki; Kashihara, Kazuhiko; Yonekura, Nobuaki; Nakajima, Takashi

\section{CITATION:}

Maurya, Sandeep Kumar ...[et al]. Rapid formation of nanostructures in Au films using a CO laser. Applied Surface Science 2018, 427(Part B): 961-965

\section{ISSUE DATE:}

2018-01-01

URL:

http://hdl.handle.net/2433/259226

\section{RIGHT:}

(c) 2017. This manuscript version is made available under the CC-BY-NC-ND 4.0 license

http://creativecommons.org/licenses/by-nc-nd/4.0/; The full-text file will be made open to the public on 1 January

2020, in accordance with publisher's 'Terms and Conditions for Self-Archiving'.; This is not the published version. Please cite only the published version.; この論文は出版社版でありません。引用の際には出版社版をご確認ご利用ください。 


\title{
Rapid formation of nanostructures in Au films using a $\mathrm{CO}_{2}$ laser
}

\author{
Sandeep Kumar Maurya ${ }^{a}$, Yuki Uto ${ }^{a}$, Kazuhiko Kashihara ${ }^{a}$, Nobuaki Yonekura ${ }^{b}$, and \\ Takashi Nakajima ${ }^{a, *}$ \\ ${ }^{a}$ Institute of Advanced Energy, Kyoto University, Gokasho, Uji, Kyoto 611-0011, Japan \\ ${ }^{b}$ Faculty of Sciences, University of the Ryukyus, Nishihara-cho, Okinawa 903-0213, Japan \\ *e-mail: nakajima@iae.kyoto-u.ac.jp
}

\begin{abstract}
We systematically investigate the formation of nanostructures in magnetron-sputtered Au films using a $\mathrm{CO}_{2}$ laser. By comparing the optical properties and surface morphologies of $\mathrm{Au}$ films on different kinds of substrates before and after laser irradiation with different laser powers and irradiation times, we find that the nanostructures are most rapidly formed in the Au film with $5 \mathrm{~nm}$ thickness on a thin glass substrate. With the laser power of $6 \mathrm{~W}$ and a beam diameter of $\sim 10 \mathrm{~mm}$ at the Au film, only a few tens of seconds of irradiation time is sufficient to induce nanostructures with the area size of $\sim 10 \mathrm{~mm}$ in the $5 \mathrm{~nm}$ Au film on a thin glass substrate.
\end{abstract}

\section{Introduction}

Over the decade, nanoparticles (NPs) have been of great interest due to its remarkable application in various fields [1-6]. Synthesis and characterization of nanoparticles have been the main issues, because NPs possess novel chemical, electronic, optical, and magnetic properties. One of the most important and useful features of NPs is a presence of surface plasmon resonance (SPR) [7]. It was found that the peak position and width of SPR primarily depend on the particle size, particle shape, and the surrounding environment [8-10]. SPR is extensively used to enhance, for example, the Raman signals from chemical or biological systems. This is so-called surface enhanced Raman scattering (SERS) [11-13].

Although there is no doubt that NPs are very useful for various applications, it is not so easy to uniformly disperse synthesized NPs on a target material, since aggregation of NPs can take place. In some cases, fabricating a thin film first on a target material, and then induce nanostructures in it by thermal or laser annealing may be more convenient. Indeed, it has been demonstrated that thermal annealing of $\mathrm{Au}$ and $\mathrm{Cu}$ films leads to the formation of nanostructures [14-18]. Similarly, laser annealing can also induce nanostructures on Au and other metallic films [19-23] with the main difference that laser annealing can induce local 
nanostructures at the desired spot on the film. Effect of laser annealing has also been reported for bimetal ( $\mathrm{Au} / \mathrm{Ag})$ films [24] and other inorganic films [25, 26]. So far, most of the existing studies for laser annealing of Au films employs UV [19-21, 24-26] or visible laser pulses [22, $23,26]$ so that the laser pulse energy is absorbed by the film itself to melt the film and induce liquid phase dewetting. Accordingly, the substrate serves as a heat dissipater. Only a few studies have reported the effects of laser annealing with mid-infrared (mid-IR) laser pulses [2731] in which the mid-IR laser pulse energy is mainly absorbed by the substrate to induce nanostructured particles in a dielectric matrix $[27,29,31]$ or to induce nanostructures in the metallic film itself [28, 30]. Although there is no clear statement in Refs. [28] and [30] for the formation mechanism of nanostructures in the Au and Ag films it is presumably liquid-phase dewetting, since the $\mathrm{CO}_{2}$ laser beam is focused to the diameter of 30-200 $\mu \mathrm{m}$ and the scan speed of the beam over the film is fast so that the effective irradiation time for a given segment is very short (presumably less than one second).

The purpose of this study is to investigate the formation of nanostructures in the magnetronsputtered $\mathrm{Au}$ films using a $\mathrm{CO}_{2}$ laser. Similar to the related studies [27-31] the energy of the $\mathrm{CO}_{2}$ laser is mainly absorbed by the glass substrate with which the Au film is heated. Through the comparison of optical properties and surface morphologies of Au films with different thicknesses on different kinds of substrates by varying the laser power and irradiation time, we find that the nanostructures can be very rapidly formed in a $5 \mathrm{~nm} \mathrm{Au}$ film on a thin glass substrate. Unlike the related studies [28, 30], however, our $\mathrm{CO}_{2}$ laser beam is not focused (diameter $10 \mathrm{~mm}$ at the target) and the laser power is very modest $(<6 \mathrm{~W})$. As a result, the film temperature during the laser irradiation stays well below the melting point of $\mathrm{Au}$, and the formation mechanism of nanostructures in Au films on glass substrates is solid-state dewetting [32] in our case.

\section{Experimental Procedure}

The substrates we use for this study are cover glass (borosilicate glass, thickness $0.15 \mathrm{~mm}$ ), slide glass (crown glass, thickness $1 \mathrm{~mm}$ ), fused silica (thickness $2 \mathrm{~mm}$ ), and $\mathrm{CaF}_{2}$ (thickness $1 \mathrm{~mm}$ ) substrates, as summarized in Table 1. From Table 1 we find that the transmittance of the substrates other than that of $\mathrm{CaF}_{2}$ is practically 0 at $10.6 \mu \mathrm{m}$. Before sputtering all the substrates are soaked into the mixture of $\mathrm{H}_{2} \mathrm{O}_{2}$ and ammonium hydroxide for $30 \mathrm{~min}$, and then acetone for $10 \mathrm{~min}$, and finally rinsed with deionized water. After the above pretreatment $\mathrm{Au}$ films are deposited onto the substrates by magnetron sputtering (MSP-mini, Vacuum Device Ltd.) using an Au target (purity 99.95\%). By measuring the sputtered Au film thickness with 
a profiler (P-16+ stylus profiler, KLA-Tencor) we have confirmed that we can fabricate Au films with desired film thicknesses by controlling the sputtering time with the accuracy of about $\pm 0.2 \mathrm{~nm}$. The surface morphology of the bare substrates as well as Au films before and after laser annealing are measured over the area of $1 \mu \mathrm{mx} 1 \mu \mathrm{m}$ using atomic force microscope (AFM) (VN-8000, Keyence). The optical properties of $\mathrm{Au}$ films are measured using a CCD spectrometer (USB2000+, Ocean Optics).

For laser annealing of Au films, we employ a $\mathrm{CO}_{2}$ laser (AL30P, Access Laser Co.) at 10.6 $\mu \mathrm{m}$. Its peak power, repetition rate, and pulse duration are, respectively, $60 \mathrm{~W}, 2.5 \mathrm{kHz}$, and $100-400 \mu$ s with a rising and falling time of $\sim 100 \mu$ s each, depending on the laser power. The laser power we employ in this study ranges from 2.5 to $8 \mathrm{~W}$, which corresponds to the pulse energy of 1 to $3.2 \mathrm{~mJ} /$ pulse. The laser beam has a nearly Gaussian transverse mode with $\mathrm{M}^{2} \sim 1.1$, and its diameter is $\sim 10 \mathrm{~mm}$ at the film position. The $\mathrm{CO}_{2}$ laser is irradiated from the front side of the film, and the temperature of the Au film during laser irradiation is measured using a thermocouple with a size of $\sim 1 \mathrm{~mm}$.

Table 1 Properties of the employed substrates

\begin{tabular}{ccccc}
\hline Substrate & Cover glass & Slide glass & Fused silica & $\mathrm{CaF}_{2}$ \\
\hline Substrate thickness $(\mathrm{mm})$ & 0.15 & 1 & 2 & 1 \\
Surface roughness $(\mathrm{nm})$ & 2.7 & 2.5 & 1.9 & 2.1 \\
Transmittance at $10.6 \mu \mathrm{m}$ & 0 & 0 & 0 & 0.36 \\
\hline
\end{tabular}

\section{Results and Discussions}

Since a sputtered $\mathrm{Au}$ film itself does not have a SPR at the $\mathrm{CO}_{2}$ laser wavelength, the laser energy is mostly absorbed by the substrate. Therefore, the choice of the substrate would influence the efficiency of $\mathrm{CO}_{2}$ laser annealing. In Fig. 1 we show the optical absorption spectra and AFM images of laser-annealed $5 \mathrm{~nm} \mathrm{Au}$ films deposited on four different kinds of substrates listed in Table 1, i.e., cover glass, slide glass, fused silica, and $\mathrm{CaF}_{2}$ substrates. The employed laser power and irradiation time are $6 \mathrm{~W}$ and 1 minute, respectively. The absorption spectrum of the 5nm Au film on a cover glass (red curve of Fig. 1(a)) shows the SPR of Au 


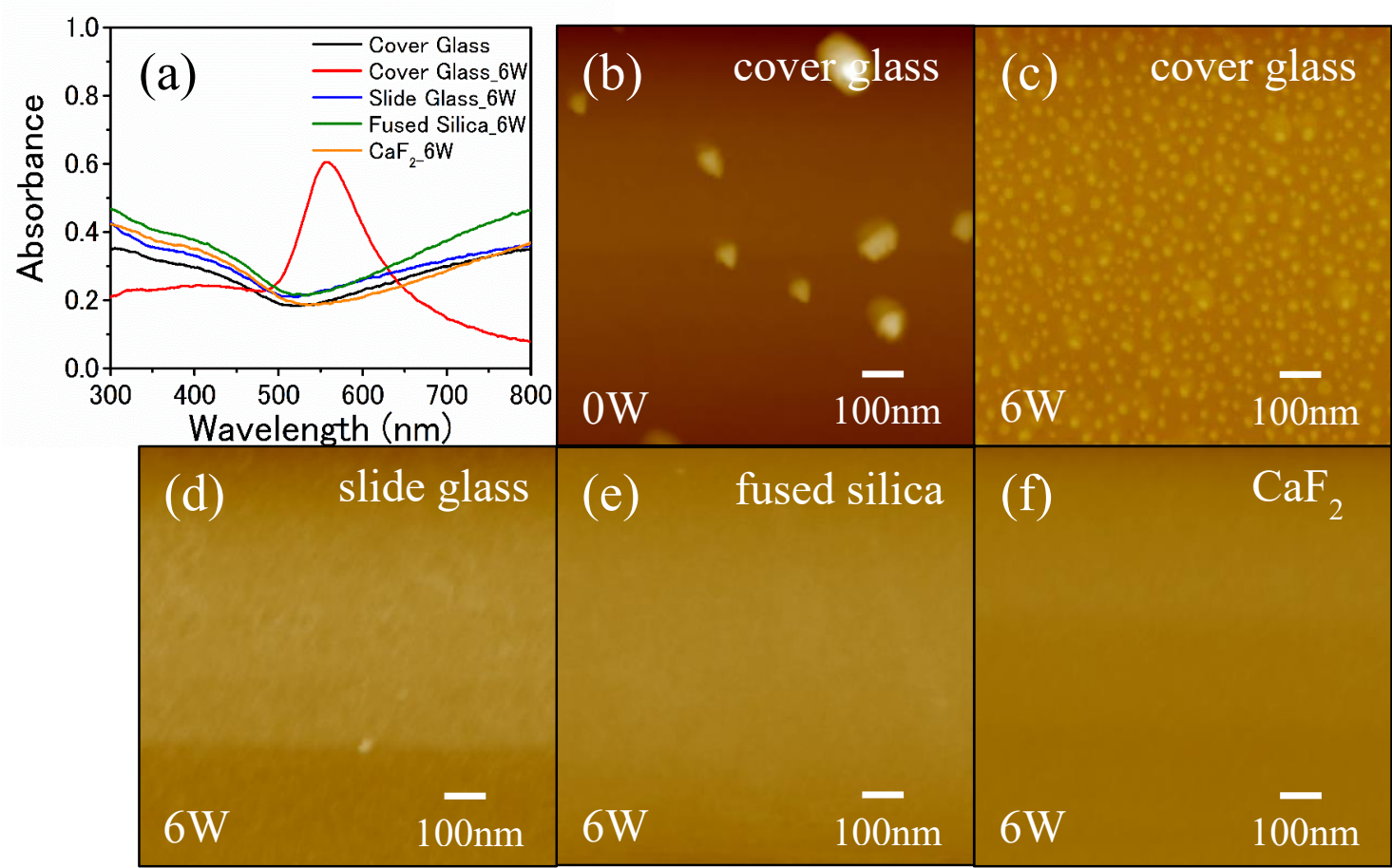

Fig. 1. (a) Comparison of optical absorption spectra and (b)-(f) the respective AFM images of the $5 \mathrm{~nm} \mathrm{Au}$ films on different substrates by $\mathrm{CO}_{2}$ laser annealing. Employed substrates are (b) and (c) cover glass, (d) slide glass, (e) fused silica, and (f) $\mathrm{CaF}_{2}$ substrates, respectively. Employed laser power and irradiation time for (c)-(f) are $6 \mathrm{~W}$ and 1 minute. (b) shows the AFM image of the cover glass before annealing.

centered at around $550 \mathrm{~nm}$, which implies that the nanostructures of Au have been formed by laser irradiation. Formation of nanostructures of metallic films is caused by the well-known dewetting mechanism, which was first found for thin polymer and then metallic films by thermal annealing [33-35]. Indeed, the absorption spectrum by the $\mathrm{CO}_{2}$ laser annealing resembles the one for the $25 \mathrm{~nm}$ Au film after thermal annealing at $400-500{ }^{\circ} \mathrm{C}$ [15]. Except for the case of cover glass, however, the annealing effect is almost negligible. All these observations can be well understood if we recall that the substrate, rather than the Au film, is the main absorber of $\mathrm{CO}_{2}$ laser energy, and upon energy absorption it also serves as a heat sink: The temperature increase of a thicker or more transparent substrate is expected to be smaller. To confirm this interpretation we measure the temperatures of the $5 \mathrm{~nm}$ Au films on the different substrates at the laser power of $6 \mathrm{~W}$, and obtain $497,193,198$, and $143{ }^{\circ} \mathrm{C}$, respectively, for the cover glass, slide glass, fused silica, and $\mathrm{CaF}_{2}$ substrates. As expected, the substrate temperatures are quite different for the different substrates irradiated at the same laser power, which is mainly due to their different thicknesses and transmittances, and this explains why only the $5 \mathrm{~nm}$ Au film on the cover glass shows the SPR after the 1 minute $\mathrm{CO}_{2}$ laser irradiation 


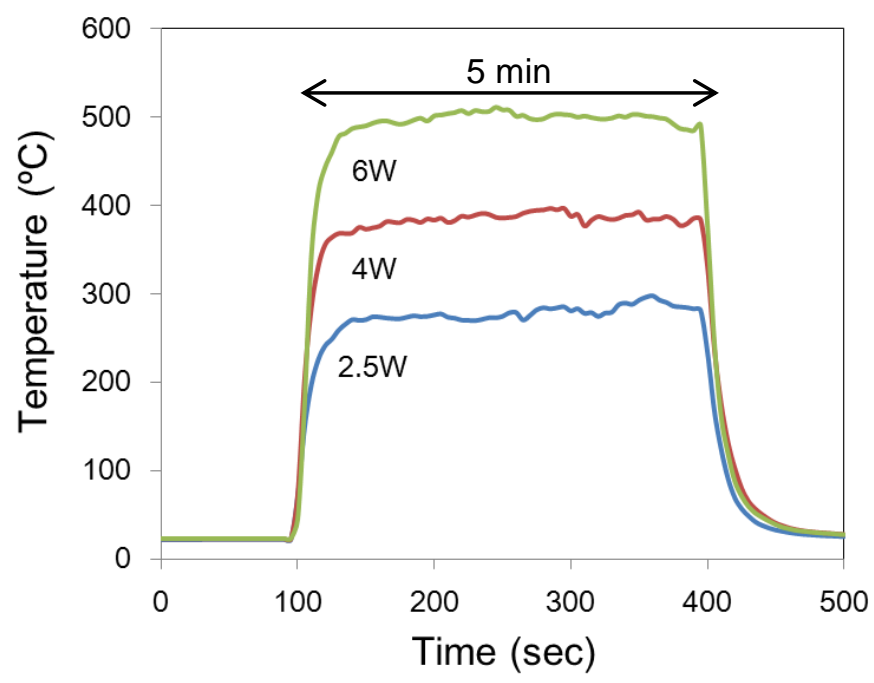

Fig. 2. Temperature of the $5 \mathrm{~nm}$ Au film on a cover glass under the different incident laser powers as a function of laser irradiation time. The $\mathrm{CO}_{2}$ laser is turned on at 100 sec, and turned off at $400 \mathrm{sec}$. The incident laser powers are 2.5 (blue) , 4 (red), and $6 \mathrm{~W}$ (green).

at $6 \mathrm{~W}$. Our results for the optical absorption spectra (Fig. 1(a)) and the AFM images (Figs. 1(c)-(f)) are consistent for all substrates.

Clearly, the choice of the cover glass as a substrate turns out to be most efficient to perform $\mathrm{CO}_{2}$ laser annealing of $\mathrm{Au}$ films, and hereafter we measure the temperature of the $5 \mathrm{~nm} \mathrm{Au}$ film on a cover glass at the different laser powers as a function of irradiation time. The results are shown in Fig. 2. After the rapid temperature increase for the first $\sim 60$ seconds the film reaches the steady-state temperature, which is different for the different laser power. They are about 280,380 , and $500^{\circ} \mathrm{C}$, respectively, at the laser power of $2.5,4$, and $6 \mathrm{~W}$. If the employed laser power is $8 \mathrm{~W}$, the temperature of the $5 \mathrm{~nm}$ Au film can be as high as $585{ }^{\circ} \mathrm{C}$. To clarify

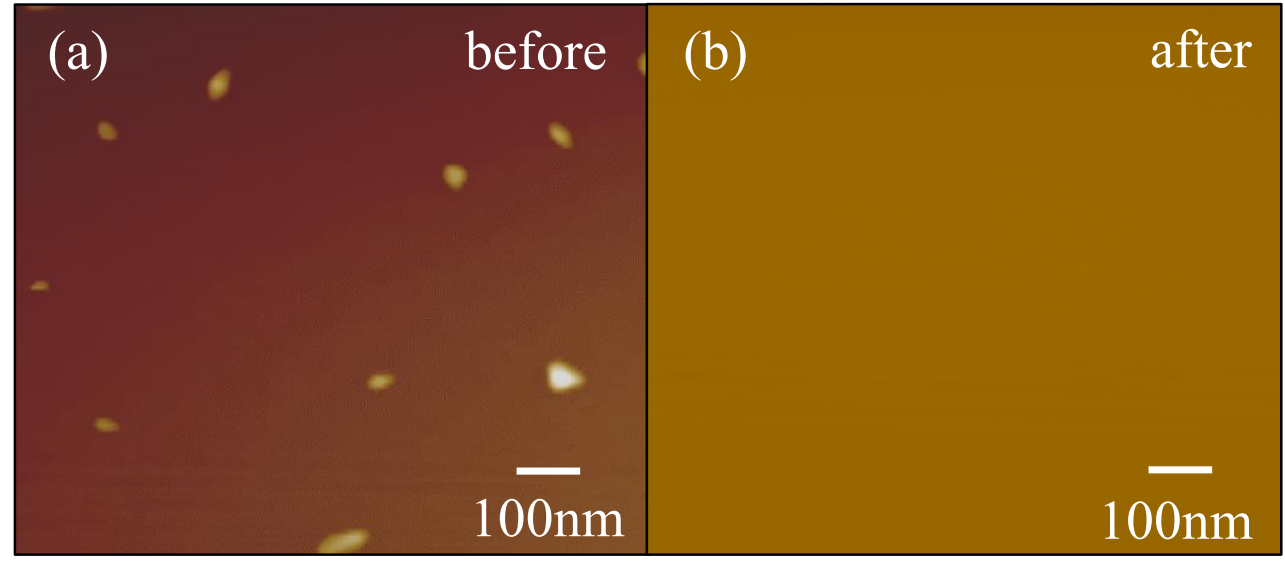

Fig. 3. AFM images of a bare cover glass (a) before and (b) after $\mathrm{CO}_{2}$ laser annealing at the laser power of $8 \mathrm{~W}$ for $5 \mathrm{~min}$. 
whether and how much change occurs on the substrate itself at such a high temperature, we check the surface morphology of a bare cover glass before and after the $\mathrm{CO}_{2}$

laser annealing at the $8 \mathrm{~W}$ laser power for 5 minutes. The results are shown in Fig. 3. The speckles before laser irradiation (Fig. 3(a)) disappear after laser irradiation (Fig. 3(b)).
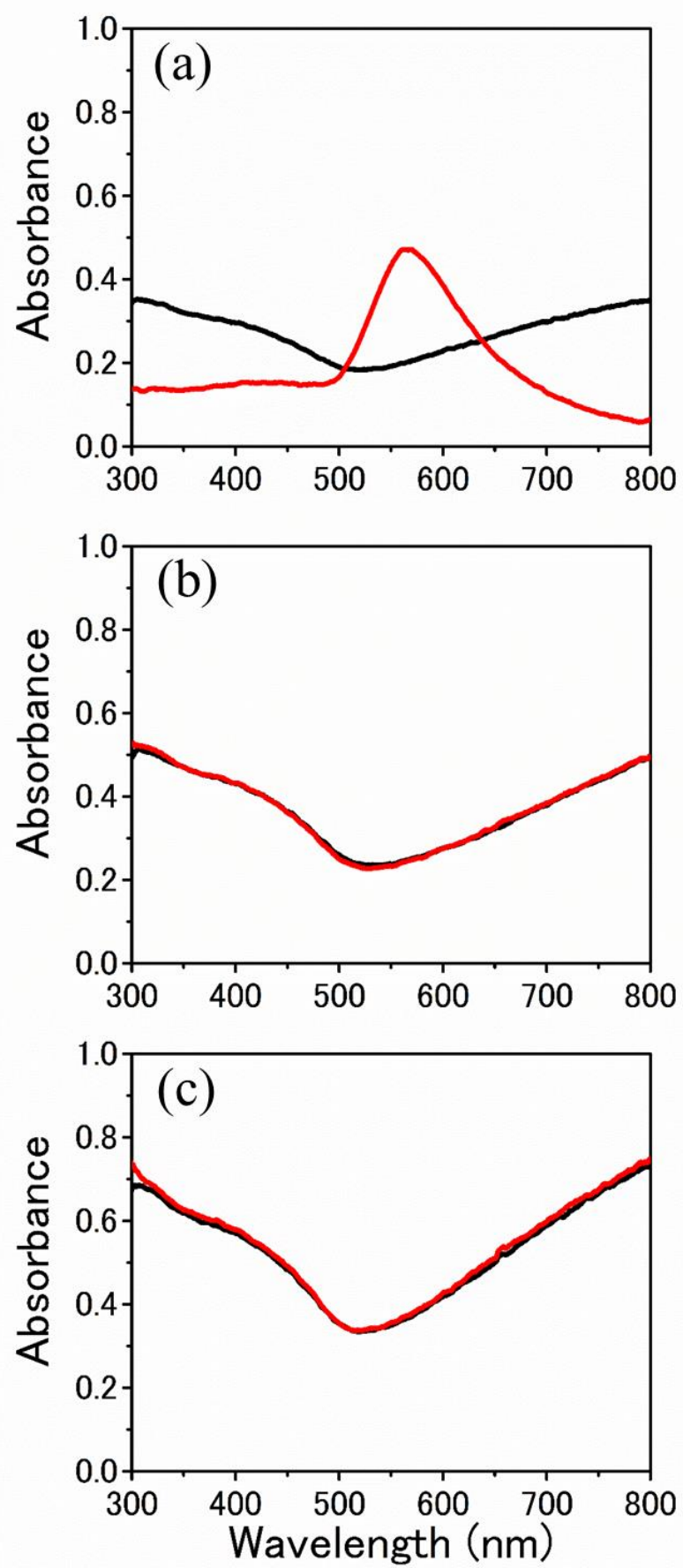

Fig. 4. Optical absorption spectra of $\mathrm{Au}$ films on cover glasses before and after $\mathrm{CO}_{2}$ laser annealing at $8 \mathrm{~W}$ laser power for 1 minute. The $\mathrm{Au}$ film thickness is (a) 5, (b) 7.5, and (c) $10 \mathrm{~nm}$, respectively. In all (a)-(c), black and red curves represent the spectra before and after annealing. 
Now, we compare the annealing effect of Au films with different thicknesses (5, 7.5, and 10 $\mathrm{nm}$ ) on the cover glass. The results at the laser power of $8 \mathrm{~W}$ for 1 minute are shown in Fig. 4. From Fig. 4, we notice that the thickness of the Au film must be sufficiently thin to induce nanostructures with our $\mathrm{CO}_{2}$ laser. Corresponding to Fig. 4(a) for the film thickness of $5 \mathrm{~nm}$, the surface roughness increases from $\sim 0.3 \mathrm{~nm}$ (excluding the speckles) to $\sim 4.3 \mathrm{~nm}$, which also indicates the formation of nanostuctures on the $5 \mathrm{~nm} \mathrm{Au}$ film by $\mathrm{CO}_{2}$ laser annealing. In contrast, there is practically no change in the absorption spectra when the Au film thickness is 7.5 and $10 \mathrm{~nm}$. To understand why the nanostructures are not formed for the 7.5 and $10 \mathrm{~nm}$ films we measure the film temperature at the laser power of $8 \mathrm{~W}$ to find that they are 244 and $217^{\circ} \mathrm{C}$, respectively, which are significantly lower than $585^{\circ} \mathrm{C}$ mentioned before for the $5 \mathrm{~nm}$ film on the cover glass at the same laser power. These differences must arise from the fact that all the $\mathrm{Au}$ films in this study are irradiated from the front side of the film. Namely, the transmittance of the $\mathrm{CO}_{2}$ laser through the $\mathrm{Au}$ film seems to rapidly drop as the $\mathrm{Au}$ film thickness increases from 5 to $7.5 \mathrm{~nm}$, while it does not drop so much when the film thickness further increases from 7.5 to $10 \mathrm{~nm}$, as the measured film temperatures suggest. In terms of the film structure there must be a transition from the island to uniform structure as the film thickness increases from 5 to $10 \mathrm{~nm}$.

To investigate the relation of employed laser power and induced nanostructures in the $\mathrm{Au}$ films, we now vary the $\mathrm{CO}_{2}$ laser power for the fixed irradiation time of 5 minutes, and take the optical absorption spectra and AFM images. Fig. 5 shows the results. Note that the speckles in Fig. 5(a), which are the same with those in Fig. 3(a), are still observed in Fig. 5(b) after the $2.5 \mathrm{~W}$ laser irradiation for 5 minutes. This implies that the $2.5 \mathrm{~W}$ laser irradiation does not sufficiently heat the substrate and the film (see Fig. 2) to induce nanostructures in the Au film, as the optical absorption spectrum in Fig. 5(f) also implies. Obviously, the laser power of more than $\sim 4 \mathrm{~W}$ is necessary to induce sufficient nanostructures (Fig. 5(c)) within 5 minutes so that a clear SPR emerges (Fig. 5(g)). Although the laser parameters are different, our results of surface morphology for increasing laser power are qualitatively similar to the change of nanoparticle size as the laser fluence increases [30]. 

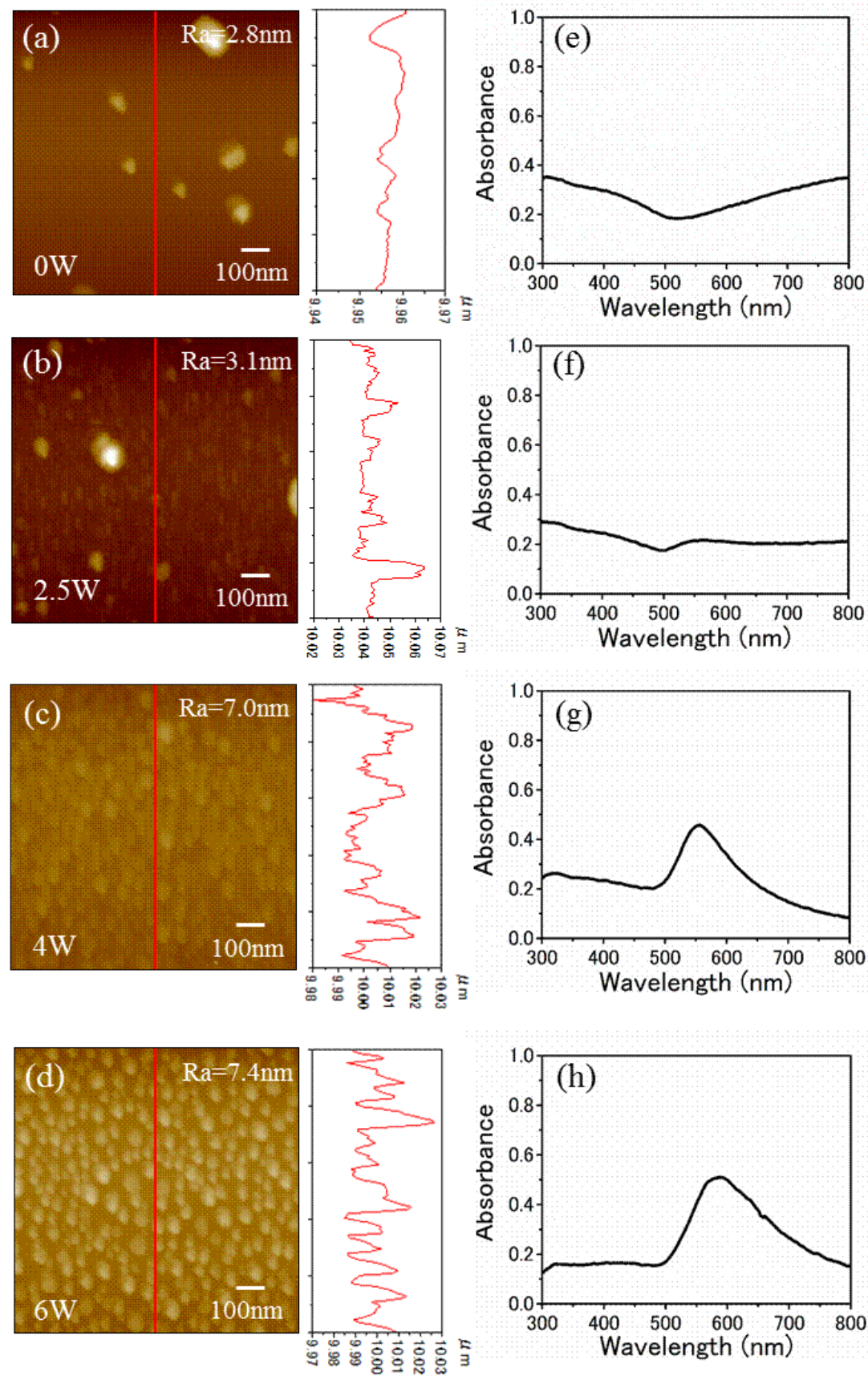

Fig. 5. AFM images (left column) and the optical absorption spectra (right column) of $5 \mathrm{~nm}$ Au films on cover glasses after $\mathrm{CO}_{2}$ laser annealing at different laser powers. The employed laser powers are (a, e) 0 , (b, f) 2.5, (c, g) 4, and (d, h) $6 \mathrm{~W}$, respectively. Irradiation time is 5 minutes for all cases. The spatial variation of surface roughness is also plotted along the vertical line in the respective AFM image. $R_{a}$ 's in panels (a)-(d) represent the arithmetic surface roughness. Note that the vertical scale of the curves of surface roughness shown on the right side of panels (a)-(d) is not calibrated, and does not represent the local film thickness itself. 
As demonstrated above, $\mathrm{CO}_{2}$ laser annealing of $5 \mathrm{~nm}$ Au film on a cover glass at $8 \mathrm{~W}$ for 1 minute (Fig. 4(a)) or $>4 \mathrm{~W}$ for 5 minutes (Figs. 5(g) and (h)) leads to the formation of nanostructures, as confirmed by the emergence of SPR in the optical absorption spectra. To better understand the mechanism of $\mathrm{CO}_{2}$ laser annealing we measure the optical absorption spectra and surface morphology of $5 \mathrm{~nm}$ Au films on cover glasses at different irradiation times at the fixed laser power of $6 \mathrm{~W}$. The results are shown in Fig. 6. From Fig. 6 we find that the nanostructures start to emerge within only 6 seconds (Figs. 6(a) and (b)), and the nanostructures become finest after the irradiation of 20 seconds (Fig. 6(d)). Further irradiation time results in the larger nanostructures, which imply the coalescence of finer nanostructures, as we notice by
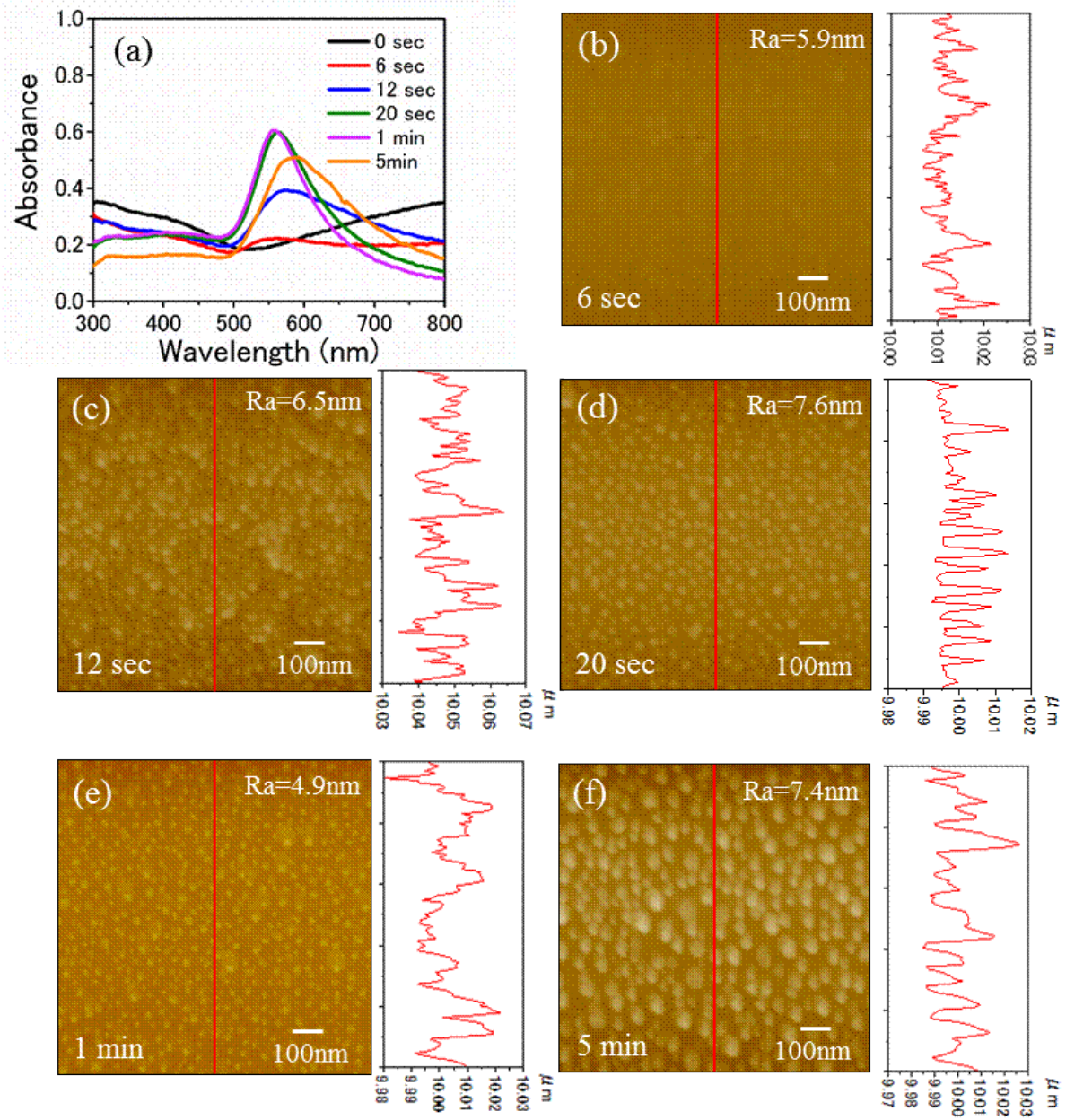

Fig. 6. (a) Comparison of optical absorption spectra and (b)-(f) the respective AFM images of the $5 \mathrm{~nm} \mathrm{Au}$ films by $\mathrm{CO}_{2}$ laser annealing with different irradiation times. Annealing times are (b) 6, (c) 12, and (d) $20 \mathrm{sec}$, and (e) 1 and (f) 5 minutes, respectively, and the laser power is $6 \mathrm{~W}$ for all cases. The spatial variation of surface roughness is also plotted along the vertical line in the respective AFM image. $R_{a}$ 's in panels (b)-(f) represent the arithmetic surface roughness. Note that the vertical scale of the curves of surface roughness shown on the right side of panels (a)-(d) is not calibrated, and does not represent the local film thickness itself. 
going from Figs. 6(d) to (f). This is consistent with the optical absorption spectra in Fig. 6(a) for the irradiation times of 20 seconds $\rightarrow 1$ minute $\rightarrow 5$ minutes.

\section{Conclusion}

In conclusion, we have carried out the systematic study on the formation of nanostructures in magnetron-sputtered $\mathrm{Au}$ films using a mid-infrared laser $\left(\mathrm{CO}_{2}\right.$ laser). For the mid-infrared laser, the primary absorber of laser energy is a glass substrate, and the laser-heated substrate anneals the Au film on it. With the laser system we have (wavelength $10.6 \mu \mathrm{m}$, maximum laser power $\sim 10 \mathrm{~W}$, pulse duration 100-400 $\mu \mathrm{s}$, beam diameter at the Au film $\sim 10 \mathrm{~mm}$, and repetition rate $2.5 \mathrm{kHz}$ ), we are able to induce nanostructures on a $5 \mathrm{~nm} \mathrm{Au}$ film sputtered on a cover glass within a few minutes of irradiation at the laser power of $>4 \mathrm{~W}$. As the laser power increases the required irradiation time to induce the nanostructures becomes significantly shorter. At $4 \mathrm{~W}$ the necessary irradiation time is about 5 minutes, while at $6 \mathrm{~W}$ it is only $10-20$ seconds. Because high power $\mathrm{CO}_{2}$ lasers are commercially available at a reasonable cost due to the industrial use they can be a convenient tool to quickly fabricate metallic films with nanostructures.

\section{Acknowledgement}

This work was supported by a Grant-in-Aid for Scientific Research from the Ministry of Education, Culture, Sports, Science and Technology of Japan, and Amada Foundation.

\section{References}


1. M. Bruchez, M. Moronne, P. Gin, S. Weiss, A.P. Alivisatos, Semiconductor Nanocrystal as fluorescent biological labels, Science 281 (1998) 2013.

2. S. Wang, N. Mamedova, N.A. Kotov, W. Chen, J. Studer, Antigen/antibody immunocomplex from CdTe nanoparticle bioconjugate, Nano Lett. 2 (2002) 817.

3. J. Ma, H. Wong, L.B. Kong, K.W. Peng, Biomimetic processing of nanocrystallite bioactive apatile coating on titanium, Nanotechnology 14 (2003) 619.

4. J.M. Nam, C.C. Thanxton, C.A. Mierkin, Nanoparticles-based bio-bar codes for the ultrasensitive detection of proteins, Science 301 (2003) 1884.

5. O.V. Salata, Applications of nanoparticles in biology and medicine, $\mathbf{J}$ Nanobiotechnol. 2 (2004) 3.

6. S. Eustis, M.A. El-Sayed, Why gold nanoparticles are more precious than pretty gold: Nobel metal surface plasmon resonance and its enhancement of the radiative and nonradiative properties of nanocrystals of different shapes, Chem. Soc. Rev. 35 (2006) 209.

7. K.A. Willets, R.P. Van Duyne, Localized Surface Plasmon Resonance Spectroscopy and Sensing, Annu. Rev. Phys. Chem. 58 (2007) 267.

8. K.-S. Lee, M.A. El-Sayed, Gold and silver nanoparticles in sensing and imaging: Sensitivity of plasmon response to size, shape, and metal composition, J. Phys. Chem. B 110 (2006) 19220.

9. K.L. Kelly, E. Coronado, L.L. Zhao, and G.C. Schatz, The optical properties of metal nanoparticles: the influence of size, shape, and dielectric environment, J. Phys. Chem. B 107 (2003) 668.

10. S. Link, C. Burda, Z.L. Wang, M.A. El-Sayed, "Electron dynamics in gold and goldsilver alloy nanoparticles: The influence of a non-equilibrium electron distribution and the size dependence of the electron-phonon relaxation, J. Chem. Phys. 111 (1999) 1255.

11. A.K. Sharma, R. Jha, B.D. Gupta, Fiber-Optic sensors based on surface plasmon resonance: A Comprehensive Review, IEEE Sensor J. 7 (2007) 1118.

12. C. da Silva Moreira, L.C. Oliveira, R. Fischer, E.S. Medeiros, A.M.N. Lima, H. Neff, Polymer-based surface plasmon resonance biochip: construction and experimental aspects, Res. Biomed. Eng. 32 (2016) 92.

13. E.C. Le Ru, E. Blackie, M. Meyer, P.G. Etchegoin, Surface Enhanced Raman scattering enhancement factors: A comprehensive study, J Phys. Chem. C 37 (2007) 13794. 
14. R.H. Doremus, Optical properties of thin metallic films in island form, J Appl. Phys. 37 (1966) 2775.

15. A. Serrano, O. Rodríguez de la Fuente, M.A. García, Extended and localized surface plasmons in annealed Au films on glass substrates, J Appl. Phys. 108 (2010) 074303.

16. P.C. Lansåker, G.A. Niklasson, C.G. Granqvist, Thin gold films on $\mathrm{SnO}_{2}: \mathrm{In}$ : Temperature-dependent effects on the optical properties, Thin Solid Film 520 (2012) 3688.

17. R. Bernardo-Gavito, A. Serrano, M.A. García, R. Miranda, D. Granados, Local characterization of the optical properties of annealed Au films on glass substrates, $\mathbf{J}$ Appl. Phys. 114 (2013) 164312.

18. G. Andreasen, P.L. Schilardi, O. Azzaroni, R.C. Salvarezza, Thermal annealing of patterned metal surfaces," Langmuir 18 (2002) 10430.

19. S.J. Henley, J.D. Carey, S.R.P. Silva, Pulsed-laser-induced nanoscale island formation in thin metal-on-oxide films, Phys. Rev. B 72 (2005) 195408.

20. S. Imamovaa, N. Nedyalkova, A. Dikovskaa, P. Atanasova, M. Sawczakb, R. Jendrzejewski, G. Sliwinski, M. Obara, Near field properties of nanoparticle arrays fabricated by laser annealing of thin Au and Ag films, Appl. Surf. Sci. 257 (2010) 1075.

21. Y. Fang, Y. Hou, F. Teng, Z. Lou, A. Tang, B. Zhang, L. Meng, Y. Ning, L. Lu Characterization of nanoscale clusters fabricated by pulsed laser irradiation of thin $\mathrm{Au}$ films, App. Surf. Sci. 273 (2013) 625.

22. K. Ratautas, M. Gedvilas, G. Raciukaitis, A. Grigonis, Nanoparticle formation after nanosecond-laser irradiation of thin gold films, J Appl. Phys. 112 (2012) 013108.

23. R. Yu, T. Shibayama, X. Meng, S. Takayanagi, Y. Yoshida, S. Yatsu, S. Watanabe, Effects of nanosecond-pulsed laser irradiation on nanostructure formation on the surface of thin Au films on $\mathrm{SiO}_{2}$ glass substrates, Appl. Surf. Sci. 289 (2014) 274.

24. N.N. Nedyalkov, R. Nikov, A. Og. Dikovska, P.A. Atanasov, G. Obara, M. Obara, Laser annealing of bimetal thin films: A route of fabrication of composite nanostructures, Appl. Surf. Sci. 258 (2012) 9162.

25. W.J. Baumgardner, J.J. Choi, K. Bian, L.F. Kourkoutis, D.-M. Smilgies, M.O. Thompson, T. Hanrath, Pulsed laser annealing of thin films of self-assembled nanocrystals, ACS Nano 5 (2011) 7010. 
26. E. Cappelli, C. Scilletta, S. Orlando, V. Valentini, M. Servidori, Laser annealing of amorphous carbon films, Appl. Surf. Sci. 255 (2009) 5620.

27. A. Tewary, R.D. Kekatpure, M.L. Brongersma, Controlling defect and Si nanoparticle luminescence from silicon oxynitride films with $\mathrm{CO}_{2}$ laser annealing, Appl. Phys. Lett. 88 (2006) 093114.

28. P. Nyga, V.P. Drachev, M.D. Thoreson, V.M. Shalaev, Mid-IR plasmonics and photomodification with Ag films, Appl. Phys. B 3 (2008) 59.

29. C.K. Chung, C.H. Li, T.S. Chen, Synthesis and characteristics of nanostructured silicon-rich nitride thin films using modified long-wavelength $\mathrm{CO}_{2}$ laser annealing, Laser Phys. Lett. 12 (2015) 096003.

30. M.D. Ooms, Y. Jeyaram, D. Sinton, Disposable plasmonics: rapid and inexpensive large area patterning of plasmonic structures with $\mathrm{CO}_{2}$ laser annealing, Langmuir 31 (2015) 5252.

31. A. Halabica, J.C. Idrobo, S.T. Pantelides, R.H. Magruder III, S.J. Pennycook, R.F. Haglund, Jr., Pulsed infrared laser annealing of gold nanoparticles embedded in a silica matrix, J Appl. Phys. 103 (2008) 083545.

32. C.V. Thompson, Solid-state dewetting of thin films, Annu. Rev. Mater. Res. 42 (2012) 399.

33. R Günter, Dewetting of thin polymer films, Phys. Rev. Lett. 68 (1992) 75.

34. R. Xie, A. Karin, J.F. Douglas, C.C. Han, R.A. Weiss, Spinodal dewetting of thin polymer films, Phys. Rev. Lett. 81 (1998) 1251.

35. J. Bischof, D. Scherer, S. Herminghaus, P. Leiderer, Dewetting modes of thin metallic films: nucleation of holes and spinodal dewetting, Phys. Rev. Lett. 77 (1996) 1536. 